University of Wollongong

Research Online

Faculty of Science, Medicine and Health -

Papers: part A

Faculty of Science, Medicine and Health

$1-1-2015$

\title{
Potential of establishing a 'global standardised growth curve' (gSGC) for optical dating of quartz from sediments
}

\author{
Bo Li \\ University of Wollongong, bli@uow.edu.au \\ Richard G. Roberts \\ University of Wollongong, rgrob@uow.edu.au \\ Zenobia Jacobs \\ University of Wollongong, zenobia@uow.edu.au \\ Sheng-Hua Li \\ University of Hong Kong, shli@hku.hk
}

Follow this and additional works at: https://ro.uow.edu.au/smhpapers

Part of the Medicine and Health Sciences Commons, and the Social and Behavioral Sciences

Commons

\section{Recommended Citation}

Li, Bo; Roberts, Richard G.; Jacobs, Zenobia; and Li, Sheng-Hua, "Potential of establishing a 'global standardised growth curve' (gSGC) for optical dating of quartz from sediments" (2015). Faculty of Science, Medicine and Health - Papers: part A. 2761.

https://ro.uow.edu.au/smhpapers/2761

Research Online is the open access institutional repository for the University of Wollongong. For further information contact the UOW Library: research-pubs@uow.edu.au 


\title{
Potential of establishing a 'global standardised growth curve' (gSGC) for optical dating of quartz from sediments
}

\author{
Abstract \\ We report investigations of the optically stimulated luminescence (OSL) signals of sedimentary quartz \\ from different regions of Asia, Africa, Europe and North America using a single-aliquot regenerative-dose \\ (SAR) procedure. We show that variations in the shape of dose response curves (DRCs), or growth curves, \\ of the test dose sensitivity-corrected OSL signals among single aliquots composed of multiple grains can \\ be greatly reduced by normalising the DRCs using one of the regenerative dose OSL signals. We refer to \\ this regenerative-dose normalisation procedure as 're-normalisation'. We find a common re-normalised \\ DRC extends to doses of $\sim 250 \mathrm{~Gy}$ for samples that differ significantly in terms of geological provenance, \\ sedimentary context and depositional age. This feature permits the development of a 'global standardised \\ growth curve' (gSGC) for OSL signals from single aliquots of quartz. The equivalent dose (De) of an \\ aliquot can be estimated from the natural signal, one regenerative dose signal and their corresponding \\ test dose signals. For the variety of samples investigated, we find that De estimates obtained from the \\ gSGC are consistent with those obtained using full SAR procedures for doses of up to $\sim 250 \mathrm{~Gy}$. Use of \\ the gSGC for single aliquots would greatly reduce the time required to estimate the De values of older \\ samples and for a large number of aliquots.

\section{Disciplines} \\ Medicine and Health Sciences | Social and Behavioral Sciences

\section{Publication Details} \\ Li, B., Roberts, R. G., Jacobs, Z. \& Li, S. (2015). Potential of establishing a 'global standardised growth \\ curve' (gSGC) for optical dating of quartz from sediments. Quaternary Geochronology, 27 94-104.
}




\section{Potential of establishing a 'global standardised \\ 2 growth curve' (gSGC) for optical dating of quartz \\ 3 from sediments}

${ }^{1}$ Centre for Archaeological Science, School of Earth and Environmental Sciences, University of Wollongong, Wollongong, NSW 2522, Australia

$7 \quad{ }^{2}$ Department of Earth Sciences, The University of Hong Kong, Pokfulam Road, Hong Kong, China

$8 \quad *$ Corresponding author: bli@uow.edu.au

9 Abstract

We report investigations of the optically stimulated luminescence (OSL) signals of sedimentary quartz from different regions of Asia, Africa, Europe and North America using a singlealiquot regenerative-dose (SAR) procedure. We show that variations in the shape of dose response curves (DRCs), or growth curves, of the test dose sensitivity-corrected OSL signals among single aliquots composed of multiple grains can be greatly reduced by normalising the DRCs using one of the regenerative dose OSL signals. We refer to this regenerative-dose normalisation procedure as 'renormalisation'. We find a common re-normalised DRC extends to doses of $\sim 250$ Gy for samples that differ significantly in terms of geological provenance, sedimentary context and depositional age. This feature permits the development of a 'global standardised growth curve' (gSGC) for OSL signals from single aliquots of quartz. The equivalent dose $\left(D_{\mathrm{e}}\right)$ of an aliquot can be estimated from the natural signal, one regenerative dose signal and their corresponding test dose signals. For the variety of samples investigated, we find that $D_{\mathrm{e}}$ estimates obtained from the gSGC are consistent with those obtained using full SAR procedures for doses of up to $\sim 250 \mathrm{~Gy}$. Use of the gSGC for single aliquots would greatly reduce the time required to estimate the $D_{e}$ values of older samples and for a large number of aliquots. 
Keywords: quartz grains, optically stimulated luminescence, standardised growth curve, dose response curve.

\section{Introduction}

The single-aliquot regenerative-dose (SAR) procedure (Galbraith et al., 1999; Murray and Wintle, 2000) has been widely adopted for optically stimulated luminescence (OSL) dating of quartz. In this procedure, the OSL signals induced by stimulating the natural dose $\left(L_{\mathrm{n}}\right)$ and each of the regenerative doses $\left(L_{\mathrm{x}}\right)$ are followed by measurements of the OSL signal induced by a test dose $\left(T_{\mathrm{x}}\right)$. The latter are used to monitor and correct for sensitivity changes associated with the various laboratory treatments, including irradiation, preheating and optical stimulation. The equivalent dose $\left(D_{\mathrm{e}}\right)$ is determined by projecting the sensitivity-corrected natural signal $\left(L_{\mathrm{n}} / T_{\mathrm{n}}\right)$ on the dose response curve (DRC), or growth curve, constructed from the sensitivity-corrected regenerative dose signals $\left(L_{\mathrm{x}} / T_{\mathrm{x}}\right)$.

A decade ago, Roberts and Duller (2004) suggested that $T_{\mathrm{x}}$ not only corrected for withinaliquot sensitivity changes but also acted as a between-aliquot normalisation step, allowing different aliquots from the same or different samples to be compared directly. This offered a potential means of creating a standardised growth curve (SGC), from which the $D_{\text {e }}$ could be estimated based solely on measurements of $L_{\mathrm{n}}$ and $T_{\mathrm{n}}$. They tested this idea on single aliquots of sand-sized quartz (six dune and beach samples from Tasmania, Australia) and silt-sized polymineral mixtures (five samples from the Chinese Loess Plateau). Their SGC approach was extended subsequently to single aliquots of quartz from different regions, including agricultural and archaeological deposits in Scotland (Burbidge et al., 2006), loess from Asia, Africa, Europe, and North America (Lai, 2006; Lai et al., 2007), sand dunes in South Africa and Florida (Telfer et al., 2008), lacustrine samples from the Qinghai-Tibetan Plateau in China (Long et al., 2010) and fluvial deposits from the Lower Mississippi Valley in the USA (Shen and Mauz, 2011). The SGC method offers a useful means of saving on instrument time when $D_{\mathrm{e}}$ estimates are required for a large number of aliquots or for high-resolution dating, with applications to 
sand-sized quartz restricted mostly to aliquots with $D_{\mathrm{e}}$ values in the low dose, near-linear region of the growth curve.

In this study, we examine the DRCs of single aliquots of quartz from sedimentary samples from different regions of Asia, Africa, Europe and North America. We show a large between-aliquot variation in the DRCs of the sensitivity-corrected OSL signals from separate aliquots of the same and different samples, and describe a normalisation method that can largely eliminate the inter-aliquot variation among the sensitivity-corrected DRCs. By comparing the normalised and sensitivitycorrected DRCs for a variety of quartz samples, we propose the possibility of constructing a 'global standardised growth curve' (gSGC) for single aliquots, providing a rapid means of reliable $D_{\mathrm{e}}$ estimation.

\section{Sample descriptions}

In this study, 19 sediment samples deposited in a variety of environmental settings in different parts of Asia, Africa, Europe and North America were examined to assess the variability in the DRCs of quartz OSL. Among the samples, 7 are new to this study and 12 are from published studies in which the raw DRC data are provided (see Table 1 for the data sources); for one of the latter samples (MST-19), both the fine-grain and coarse-grain fractions were measured (Timar-Gabor et al., 2012). The sample locations, measurement conditions and $D_{\mathrm{e}}$ ranges (or approximate $D_{\mathrm{e}}$ values) are summarised in Table 1. Sample DC-1 is a fluvial sediment from Shanxi province in China. Sample DGF-1 is a lacustrine sediment taken from the southern edge of the Mu Us Desert (MUD) in central China, and has been studied previously by Li and Li (2006). HLD-3 is a sample of dune sand taken from He Er Hong De in the Hulun Buir Desert (HBD) in northeast China (Li et al., 2002), and Sm5 is a dune sediment from the Shimao section on the southeastern margin of the Mu Us Desert (Sun et al., 1999; Li et al., 2011). MS-5450 is a Chinese loess sample collected at Mangshan in Henan, and two additional loess samples, TB-8 and TB-10, originate from Tibet (Sun et al., 2007). Despite their different geological provenances, the OSL signals of these quartz samples are dominated by the fast 
component (Fig. 1), which is the most suitable for the SAR procedure (Galbraith et al., 1999; Wintle and Murray, 2006). Additional data for samples examined in other studies were also investigated (Table 1), including loess samples from China, Germany, Romania and the USA, and fluvial deposits from Morocco and the USA (Lai et al., 2007; Shen and Mauz, 2011; Timar-Gabor et al., 2012).

\section{Experimental procedures and analytical facilities}

The 7 samples examined as part of this study were prepared for OSL analysis using routine procedures (Aitken, 1998). They were first treated with $\mathrm{HCl}$ acid and $\mathrm{H}_{2} \mathrm{O}_{2}$ solution to remove carbonates and organic matter, respectively, and then dried and sieved to obtain grains of 90-150 and 150-212 $\mu \mathrm{m}$ in diameter (Table 1). Quartz grains were separated from feldspars and heavy minerals using solutions of sodium polytungstate, and then etched with $40 \%$ hydrofluoric acid for 45 min before being given a final wash in $\mathrm{HCl}$ acid to remove any precipitated fluorides. The mineral grains were mounted on the 10-mm-diameter aluminum discs, using silicone oil as an adhesive, for optical stimulation and measurement. Any residual feldspar contamination of the quartz was checked using the OSL IR depletion ratio (Duller, 2003); none of the measured aliquots showed a significant depletion in the OSL signal following stimulation with IR photons at room temperature.

All measurements were performed on an automated Ris $\varnothing$ TL/OSL-DA-15 reader equipped with excitation units containing blue light-emitting diodes $\left(470 \pm 20 \mathrm{~nm}\right.$ at $\left.\sim 50 \mathrm{~mW} / \mathrm{cm}^{2}\right)$ and IR diodes ( $830 \pm 10 \mathrm{~nm}$ at $\sim 200 \mathrm{~mW} / \mathrm{cm}^{2}$ ) (Bøtter-Jensen et al., 2000). The OSL signals were detected by an Electron Tubes Ltd 9235B photomultiplier tube fitted with U-340 filters, and laboratory irradiations were carried out using calibrated ${ }^{90} \mathrm{Sr} /{ }^{90} \mathrm{Y}$ beta sources. All OSL stimulations were made at $125^{\circ} \mathrm{C}$ for $40 \mathrm{~s}$, following a preheat of $260^{\circ} \mathrm{C}$ for $10 \mathrm{~s}$ and a cut-heat to $220^{\circ} \mathrm{C}$ for the regenerative and test doses, respectively; these thermal treatments were chosen on the basis of dose recovery tests, which yielded measured/given dose ratios of $0.94 \pm 0.06$ for 4 aliquots of sample DC-1, $1.02 \pm 0.08$ for 6 aliquots of sample DGF-1, $1.05 \pm 0.04$ for 6 aliquots of sample HLD-3 and $0.98 \pm 0.05$ for 4 aliquots of sample MS-5450. The resulting OSL signals were calculated from the sum of counts over 
the initial $0.4 \mathrm{~s}$ of stimulation, with 'late light' subtraction (Aitken, 1998) of the background count rate over the final $5 \mathrm{~s}$ of stimulation. Table 1 summarises the preheat conditions used for the samples in the other studies, the size of the measured grains and the size of the test doses, the latter ranging from 0.7 to 25.9 Gy.

\section{An improved inter-aliquot normalisation procedure}

The basic idea of establishing a SGC is that between-aliquot variation can be normalised using $T_{\mathrm{x}}$. This assumption, however, may not be satisfied for every sample, for reasons that can be demonstrated mathematically. Assuming a single electron trap gives rise to luminescence signal $L$, (Chen et al., 2001; Wintle and Murray, 2006), the dose response for a specific aliquot or grain $(j)$ can be described using a single saturating exponential function:

$$
L_{\mathrm{j}}=S_{\mathrm{j}}(i, D)\left[N_{0} *\left(1-e^{-\frac{D}{D_{0}}}\right)\right]
$$

where $D$ is the applied radiation dose, $S_{\mathrm{j}}(i, D)$ is a function of $i$ (the number of the measurement cycle in the SAR sequence) and $D, N_{0}$ is the saturation charge population reached at infinite dose $(D=\infty)$ and $D_{0}$ is the characteristic saturation dose. $S_{\mathrm{j}}(i, D)$ describes the change in luminescence sensitivity (OSL per unit recombining charge) that occurs during measurement of the OSL at various regenerative doses, and is expected to vary from aliquot to aliquot and from grain to grain. Similarly, the test dose signal $\left(T_{\mathrm{j}}\right)$ for this aliquot or grain can be described by:

$$
T_{\mathrm{j}}=k_{\mathrm{j}} S_{\mathrm{j}}\left(i, D_{\mathrm{t}}\right)\left[N_{0} *\left(1-e^{-\frac{D_{t}}{D_{0}}}\right)\right]
$$

where $D_{\mathrm{t}}$ is the test dose and the constant $k$ describes any change in luminescence sensitivity from the natural or regenerative dose step to the test dose measurement. It then follows that the sensitivitycorrected luminescence signal $\left(L_{\mathrm{j}} / T_{\mathrm{j}}\right)$ is given by

$$
L_{\mathrm{j}} / T_{\mathrm{j}}=\left(1-e^{-\frac{D}{D_{0}}}\right) /\left[k_{\mathrm{j}}\left(1-e^{-\frac{D_{\mathrm{t}}}{D_{0}}}\right)\right]
$$


As shown from eqn. 3, the sensitivity-corrected luminescence signal for a specific aliquot or grain $\left(L_{\mathrm{j}} / T_{\mathrm{j}}\right)$ is dependent on $D_{\mathrm{t}}, D_{0}$ and $k_{\mathrm{j}}$. Because the size of the test dose will affect the size of the test dose response $\left(T_{\mathrm{j}}\right)$, Roberts and Duller (2004) suggested that the sensitivity-corrected luminescence signal $\left(L_{j} / T_{\mathrm{j}}\right)$ can be adjusted for the size of the test dose $\left(D_{\mathrm{t}}\right)$ to produce a 'standardised luminescence signal' $\left(\left(L_{j} / T_{\mathrm{j}}\right) * D_{\mathrm{t}}\right)$. This test-dose normalisation method assumes that the test dose is kept within the linear region of the DRC (i.e., the test dose is much smaller than the $D_{0}$ value). As a result, eqn. 3 can be simplified to:

$$
L_{j} / T_{j}=\frac{\left(1-e^{-\frac{D}{D_{0}}}\right)}{k_{j} \frac{D_{\mathrm{t}}}{D_{0}}}=\frac{D_{0}}{k_{j} D_{\mathrm{t}}}\left(1-e^{-\frac{D}{D_{0}}}\right)
$$

It follows that different aliquots and grains will have similar test dose-corrected OSL signals $\left[(L / T)^{*} D_{\mathrm{t}}\right]$ if they share the same $D_{0}$ and $k$ values. For young samples with $D_{\mathrm{e}}$ values in the linear region of the DRC (i.e., $D$ is much smaller than $D_{0}$ ), the function of their test dose-corrected signal can be further simplified to:

$$
\frac{L}{T} D_{\mathrm{t}}=\frac{D}{k}
$$

In eqn. 5 , the form of test dose-corrected signal $\left[(L / T) * D_{\mathrm{t}}\right]$ is dependent only on the $k$ value, so similar DRCs should be observed for aliquots and grains that have similar $k$ values (e.g., Roberts and Duller, 2004). This requirement may not be satisfied, however, because different grains may have experienced different irradiation, bleaching and thermal histories, and these factors may influence the extent of sensitivity change (i.e., the $k$ value) induced by laboratory irradiation, preheating and bleaching procedures (e.g., Murray and Wintle, 1999a, 1999b; Chen et al., 2001). As a result, the similarity in shape of DRCs for different aliquots and grains depends critically on the between-aliquot and between-grain variations in the $k$ values at low doses (eqn. 5), and on variations in both the $k$ and $D_{0}$ values at higher doses (eqn. 4). Single grains of quartz commonly exhibit large variations in $D_{0}$, resulting in DRCs that differ markedly in shape, even at quite low doses (e.g., Roberts et al., 1999; 
Jacobs et al., 2003, 2013). For single aliquots, where tens, hundreds or thousands of grains are

146 measured simultaneously, grain-averaging effects will reduce the variability in $D_{0}$ values and DRC 147 shapes.

Burbidge et al. (2006) recommended that one additional regenerative dose response should be measured to check the validity of SGC, and Telfer et al. (2008) reiterated this recommendation. Rather than using the method proposed by Burbidge et al. (2006), we propose here a method to reduce the effect of between-aliquot variation in $k$ values for normalising the DRCs of single aliquots. We achieve this by standardising the DRCs using one of the regenerative dose signals - that is, by dividing the sensitivity-corrected natural $\left(L_{\mathrm{n}} / T_{\mathrm{n}}\right)$ and regenerative-dose $\left(L_{\mathrm{x}} / T_{\mathrm{x}}\right)$ signals in each SAR cycle by the signal $\left(L_{\mathrm{r} 1} / T_{\mathrm{r} 1}\right)$ of the regenerative dose $\left(D_{\mathrm{r} 1}\right)$ chosen for normalisation. We refer to this procedure as 'regenerative-dose normalisation' or 're-normalisation'. Based on eqn. 3, it follows the re-normalised sensitivity-corrected OSL signal can be expressed as:

$$
\frac{L_{x} / T_{x}}{L_{r 1} / T_{\mathrm{r} 1}}=\left(1-e^{-\frac{D}{D_{0}}}\right) /\left(1-e^{-\frac{D_{r 1}}{D_{0}}}\right)
$$

From eqn. 6 , it can be seen that re-normalisation produces a DRC independent of $k$ and, hence, independent of the irradiation, bleaching and thermal histories of the grains comprising the different aliquots. We expect, therefore, that the re-normalisation procedure should reduce the between-aliquot variation in DRC shape to a greater extent than is achieved using the SGC method of Roberts and Duller (2004).

We recognise that the re-normalisation method cannot eliminate all inter-aliquot variation in DRC shape, because eqn. 6 is based on the assumption that $k$ is independent of the preceding dose, and this may not be true. Using the $110^{\circ} \mathrm{C}$ TL peak as a monitor of OSL sensitivity change (Murray and Roberts, 1998), Murray and Wintle (2000) found that sensitivity changes between the natural or regenerative dose step and the test dose measurement (i.e., the $k$ value) were dose-dependent for their quartz samples. They also suggested, however, that this dependency did not influence the accuracy of 
$D_{\text {e }}$ estimation using the sensitivity-corrected OSL signal (Wintle and Murray, 2006), so any dose dependency in $k$ should also not affect the accuracy of $D_{\mathrm{e}}$ estimation based on re-normalised DRCs.

To test whether the re-normalisation method can improve the standardisation of DRC shapes for different aliquots of the same sample, we compared the DRCs of six single aliquots of quartz from sample Sm5 (Fig. 2a). The sensitivity-corrected OSL signals $\left(L_{\mathrm{x}} / T_{\mathrm{x}}\right)$ show a large inter-aliquot scatter (filled diamonds, left-hand scale of Fig. 2a), which is reduced significantly (open circles, right-hand scale) when these data are re-normalised using the regenerative dose signal at 172 Gy (indicated by the arrow). The relative standard deviation (RSD) in $L_{\mathrm{x}} / T_{\mathrm{x}}$ ranges from $14 \%$ to $21 \%$ at regenerative doses of $86,172,258$ and $344 \mathrm{~Gy}$, and is reduced to $5-8 \%$ after re-normalisation. The same trend is observed for the sensitivity-corrected natural signals $\left(L_{\mathrm{n}} / T_{\mathrm{n}}\right)$, which are plotted on the $y$-axis: the RSD in $L_{\mathrm{n}} / T_{\mathrm{n}}$ is $29 \%$, decreasing to $18 \%$ after re-normalisation using the $172 \mathrm{~Gy}$ signal.

Fig. 2b-f show similar comparative plots of the DRCs for five other samples (HLD-3, TB-8, DC-1, DGF-1 and MS-5450). Four of these (HLD-3, TB-8, DC-1 and DGF-1) exhibit a similar pattern to Sm5, namely a reduced inter-aliquot scatter among the natural and regenerative dose signals after applying the re-normalisation procedure. By contrast, sample MS-5450 shows no obvious improvement after re-normalisation (Fig. 2f). The latter sample has a much smaller inter-aliquot variation in $L_{\mathrm{x}} / T_{\mathrm{x}}$ ratios than the other samples examined, which suggests that these aliquots vary much less in their $k$ values. Accordingly, $T_{\mathrm{x}}$ is sufficient to reduce the inter-aliquot variations for this particular sample, and re-normalisation offers limited additional benefit.

We note that the magnitude of reduction in scatter of the $L_{\mathrm{n}} / T_{\mathrm{n}}$ values depends on which regenerative dose signal is used for re-normalisation. Using the data of Sm5 (Fig. 2a) as an example, Fig. 3 illustrates how the choice of re-normalisation signal affects the extent of inter-aliquot variation. The RSD in the $L_{\mathrm{n}} / T_{\mathrm{n}}$ ratios (plotted on the $y$-axis) is highest before re-normalisation and is lowest using the regenerative dose signal at 86 Gy or 172 Gy for re-normalisation. These two doses are closest to the sample $D_{\text {e }}$ (Fig. 2a), and similar results were observed for the other samples. Optimum 
results were generally obtained using the regenerative dose signal that matched most closely the intensity of the natural signal (indicated by arrows in Fig. 2), which we attribute to the reduction in scatter associated with any dose dependency of $k$.

As eqn. 6 is independent of $k$, another implication is that re-normalisation should be independent of the experimental treatments applied to the regenerative and test doses. We tested this proposition on sample DGF-1 by changing the preheat and cut-heat temperatures for the regenerative and test doses, respectively, and by varying the size of test dose (Fig. 4). The test dose-corrected signals $\left[\left(L_{\mathrm{x}} / T_{\mathrm{x}}\right) * D_{\mathrm{t}}\right]$ are plotted against regenerative dose in Fig. 4a, with the natural signals shown on the $y$-axis. The between-aliquot scatter is large, suggesting that these different measurement conditions may give rise to variations in $k$. The scatter is greatly reduced after re-normalisation using the regenerative dose signal at 86 Gy and, moreover, no differences can be detected between aliquots that received different treatments. This suggests that the re-normalisation procedure can potentially generate a standardised shape for the quartz DRCs of separate aliquots of the same sample under a variety of measurement conditions.

\section{Comparing single-aliquot DRCs for different quartz samples}

For the Chinese samples examined thus far, the reduction in inter-aliquot variation achieved using the re-normalisation procedure (Fig. 2-4) indicates that between-aliquot variations in $k$ can be reduced substantially by selecting one of the regenerative dose signals for re-normalisation. We now investigate the extent to which the re-normalised DRCs for these samples are similar in overall shape.

In Fig. 5a, the test dose-corrected signals $\left[\left(L_{\mathrm{x}} / T_{\mathrm{x}}\right) * D_{\mathrm{t}}\right]$ are plotted against regenerative dose for each aliquot, revealing a large scatter in values among individual aliquots of the same and different samples; this confirms our earlier contention that $T_{\mathrm{x}}$ cannot account sufficiently for the observed variations in these samples. Fig. $5 \mathrm{~b}$ shows the re-normalised data sets, in which the $L_{\mathrm{x}} / T_{\mathrm{x}}$ ratios for individual aliquots have been multiplied by a scaling factor, such that the regenerative dose DRC for each sample passes through a re-normalised $L_{\mathrm{x}} / T_{\mathrm{x}}$ value of unity at $172 \mathrm{~Gy}$; this is equivalent to 
normalising each data set using the regenerative dose signal at $172 \mathrm{~Gy}$. The value of 172 Gy was chosen because it lies in the middle of the applied dose range (0-344 Gy), thereby providing a check on the efficacy of re-normalisation at both lower and higher doses. There is a significant reduction in inter-aliquot and inter-sample variation after this re-normalisation, with the DRCs of the different samples showing a very similar pattern of growth with dose up to $\sim 350 \mathrm{~Gy}$. This suggests that between-sample variations in $k$ have been adequately corrected for and that these samples share a similar characteristic saturation dose $\left(D_{0}\right)$.

We next explored whether these features are common to quartz samples in other regions also, using published data on sediments from Africa, Europe and North America (Table 1, Fig. 6). These studies reported only the average $L_{\mathrm{x}} / T_{\mathrm{x}}$ signal for a group of aliquots, rather than the data for individual aliquots, so we are restricted to making comparisons of the sample-average results. In addition, the exact $L_{\mathrm{x}} / T_{\mathrm{x}}$ values were not reported for the two grain-size fractions of the Romanian sample (MST-19 (FG) and MST-19 (CG); Timar-Gabor et al., 2012) or for the 'synthetic' sample TNE from Australia (created from 27 aliquots of six samples; Roberts and Duller, 2004). The DRCs for these samples are shown by dotted and dashed lines in Fig. 6, based on the curve-fitting parameters provided by the authors. For sample TNE, however, we restricted DRC construction to a maximum dose of up to $125 \mathrm{~Gy}$, as this was the dose limit used by Roberts and Duller (2004) to estimate the curve-fitting parameters. For the samples examined by Lai (2006), Lai et al. (2007) and Shen and Mauz (2011), and for the 7 samples measured for this study, the data sets are based on the average of six aliquots, with the associated standard deviations shown as error bars in Fig. 6.

For these samples, we observed a large variation in the test dose-corrected signals $\left[\left(L_{\mathrm{x}} / T_{\mathrm{x}}\right)^{*} D_{\mathrm{t}}\right]$ at 240 different regenerative doses (Fig. 6a), suggesting that $T_{\mathrm{x}}$ cannot account sufficiently for the observed 241 variations in these samples. One possible cause of this variation is the wide range in size of the test doses (0.7-25.9 Gy; Table 1), which may give rise to a test dose dependency in $\left[\left(L_{\mathrm{x}} / T_{\mathrm{x}}\right) * D_{\mathrm{t}}\right]$ (Shen and 
the trend of the DRCs in Fig. 6a, so we suggest instead that the DRC variations in Fig. 6a are due mainly to between-sample variability in the $k$ and $D_{0}$ values. The single-aliquot DRCs of the test dosecorrected signals from each sample were fitted using a single saturating exponential function $Y=A[1-$ $\left.\exp \left(-X / D_{0}\right)\right]+Y_{0}$, where $Y$ is the test dose-corrected signal, $X$ is the regenerative dose, $D_{0}$ is the characteristic saturation dose, and $A$ and $Y_{0}$ are constants. The corresponding $D_{0}$ values are summarised in Table 1. We obtained a wide range of $D_{0}$ values (from about 55 to $250 \mathrm{~Gy}$ ), but most of the $D_{0}$ values are between 100 and $150 \mathrm{~Gy}$.

If the data sets in Fig. 6a are re-normalised to unity at a regenerative dose of 172 Gy (i.e., as in Fig. 5b), then the between-sample variation is reduced significantly and, except for the fine-grain quartz sample MST-19 (FG) from Romania, the re-normalised DRCs are similar in shape up to a dose of $\sim 250$ Gy (Fig. 6b,c). Above $250 \mathrm{~Gy}$, the coarse-grain and fine-grain data sets for the Romanian sample (MST-19) appear to diverge from the general line of best fit to the other samples (Fig. 6b), but we note that the coarse-grain fraction follows the trend line much more closely than does the finegrain fraction at doses below 250 Gy (Fig. 6c). The similarity in DRC shapes observed in Fig. 6b and 6c suggests that inter-sample variation in $k$ can be corrected for using the re-normalisation procedure, at least for doses of up to $\sim 250 \mathrm{~Gy}$. At higher doses, inter-sample variations in $D_{0}$ values or samplespecific saturation limits are likely to play an increasingly important role.

From the results shown in Fig. $6 \mathrm{~b}$ and $6 \mathrm{c}$, there appear to be good prospects of establishing a 'global standardised growth curve' (gSGC) to 250 Gy for quartz samples from different regions by using the re-normalisation procedure. The data in the $0-250$ Gy dose range are well described by a single saturating exponential function of the form $Y=A\left[1-\exp \left(-X / D_{0}\right)\right]$, for which the best-fit $D_{0}$ value is $110 \mathrm{~Gy}$, and by a single saturating exponential function plus linear component (shown as the solid black line in Fig. 6b,c). The presence of such a linear component in the high-dose response of quartz OSL for some samples is not yet fully understood. As it may be a laboratory artefact, rather than reflecting the true dose response of quartz in the natural environment, it has been suggested that 
the $D_{\mathrm{e}}$ values obtained from this region should be treated with caution in the absence of independent age control (e.g., Lai, 2010; Lowick and Preusser, 2011). Table 2 lists the best-fit parameters for the latter function when applied to the re-normalised data sets of all samples (excluding the Romanian sample) in Fig. 6b (0-450 Gy) and Fig. 6c (0-250 Gy).

\section{6. $D_{\mathrm{e}}$ estimation using the global standardised growth curve}

A gSGC for quartz OSL should facilitate the rapid and reliable estimation of $D_{\mathrm{e}}$ from a large number of single aliquots, and it differs in only one significant respect from the SGC method used by previous studies (e.g., Roberts and Duller, 2004; Lai, 2006; Lai et al., 2007): the re-normalisation method requires a regenerative dose OSL signal (and its corresponding test dose signal) to be measured in addition to the sensitivity-corrected natural signal $\left(L_{\mathrm{n}} / T_{\mathrm{n}}\right)$, which is projected on to the $L_{\mathrm{x}} / T_{\mathrm{x}}$ SGC to estimate the $D_{\mathrm{e}}$. As a result, the $D_{\mathrm{e}}$ for a single aliquot of quartz can be determined from its natural signal $\left(L_{\mathrm{n}}\right)$, one regenerative dose signal $\left(L_{\mathrm{r} 1}\right)$, their corresponding test dose signals $\left(T_{\mathrm{n}}, T_{\mathrm{r} 1}\right)$, and the gSGC.

As demonstrated in Fig. 3, the chosen regenerative dose should be as close as possible in size to that of the natural dose to minimise the scatter in the re-normalised $L_{\mathrm{n}} / T_{\mathrm{n}}$ signals. It may be necessary, therefore, to choose alternative regenerative doses for different samples, resulting in a variety of renormalisation factors. The latter can be related to the gSGC as follows:

$$
\eta \frac{L}{T}=f(D)
$$

where $f(D)$ is the gSGC function (as parameterised in Table 2) and $\eta$ is the re-normalisation factor (which differs from aliquot to aliquot). The $L_{\mathrm{n}} / T_{\mathrm{n}}$ and $L_{\mathrm{r} 1} / T_{\mathrm{r} 1}$ ratios for each aliquot can then be expressed as:

$$
\eta \frac{L_{n}}{T_{n}}=f\left(D_{e}\right)
$$

and 
where $D_{r l}$ is the regenerative dose chosen for re-normalisation.

294 The re-normalisation factor $\eta$ can, thus, be determined for each aliquot as:

$$
\eta=\frac{f\left(D_{\mathrm{r} 1}\right)}{L_{\mathrm{r} 1} / T_{\mathrm{r} 1}}=\frac{f\left(D_{e}\right)}{L_{n} / T_{n}}
$$

Since all of the parameters in this equation (i.e., $f(D), D_{\mathrm{r} 1}, L_{\mathrm{n}} / T_{\mathrm{n}}$ and $L_{\mathrm{r} 1} / T_{\mathrm{r} 1}$ ) are known, the $D_{\mathrm{e}}$ can be calculated by solving eqn. 10 using an iterative method.

Here we provide a worked example using the data for a single aliquot of sample HLD-3. Based on the best-fitting parameters for the 0-250 Gy data sets in Fig. 6c (see Table 2), the function of the

For the specific aliquot chosen as an example, the values of $L_{\mathrm{n}} / T_{\mathrm{n}}$ and $L_{\mathrm{r} 1} / T_{\mathrm{r} 1}$ are $2.361 \pm 0.087$ and $2.744 \pm 0.091$, respectively, using a regenerative dose $\left(D_{\mathrm{r} 1}\right)$ of 34.4 Gy for re-normalisation.

Substituting the values of $D_{\mathrm{r} 1}, L_{\mathrm{n}} / T_{\mathrm{n}}$ and $L_{\mathrm{r} 1} / T_{\mathrm{r} 1}$ into eqn. 11 , and then solving it iteratively, gives a gSGC $D_{\mathrm{e}}$ value of $28.4 \pm 1.3 \mathrm{~Gy}$, which is consistent with the $D_{\mathrm{e}}$ of $27.3 \pm 1.3$ Gy obtained using the full SAR procedure for this aliquot.

To test the reliability of $D_{\mathrm{e}}$ estimation using the gSGC shown by the solid black line in Fig. 6c, 56 individual aliquots from the 7 Chinese samples measured in this study (Table 1) were analysed as described above, and the $D_{\mathrm{e}}$ values compared with those obtained using the full SAR procedure for each aliquot. All of the aliquots measured for these samples passed the standard tests of acceptable

311 SAR performance - that is, negligible recuperation $(<5 \%)$ and a mean recycling ratio consistent with 312 unity $(1.01 \pm 0.01)$. The parameters of the best-fitting saturating exponential plus linear gSGC (0-250

313 Gy data in Table 2) were combined with the aliquot-specific variables in eqn. 11 to estimate the gSGC 
$314 D_{\mathrm{e}}$ value for each aliquot. These values are plotted against the individual SAR $D_{\mathrm{e}}$ values in Fig. 7a 315 with the data up to 250 Gy shown as filled symbols and the data >250 Gy shown as open symbols.

316 The results shows that the $D_{\mathrm{e}}$ estimates obtained from both methods are consistent at $2 \sigma$, with just one 317 exception. The sensitivity-corrected natural signal of the latter aliquot (from sample Sm5) lies above 318 the sensitivity-corrected intensity of the largest applied regenerative dose ( $344 \mathrm{~Gy}$ ), so the $D_{\text {e }}$ was 319 estimated by extrapolation, which may account for this discrepancy. Furthermore, the extrapolated $D_{\mathrm{e}}$ 320 value of $\sim 394$ Gy for this aliquot is significantly greater than $250 \mathrm{~Gy}$, which is the maximum dose used to derive the fitting parameters of the gSGC.

The concordance between the $D_{\mathrm{e}}$ values of the two methods for 55 of the 56 aliquots is further demonstrated in Fig. $7 \mathrm{~b}$, which plots the ratios of the gSGC and SAR $D_{\mathrm{e}}$ values against the

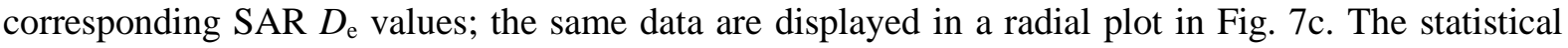
consistency of these ratios (i.e., $98 \%$ within $2 \sigma$ of unity) suggests that the gSGC method can produce reliable estimates of $D_{\mathrm{e}}$ up to $\sim 250 \mathrm{~Gy}$, and possibly to higher doses. We note that the gSGC $D_{\mathrm{e}}$ estimates have smaller analytical uncertainties than their SAR $D_{\mathrm{e}}$ counterparts, especially at higher doses. This slight increase in precision reflects the large number of data points used to constrain the fitting parameters of the gSGC, compared to the few data points used to fit the DRC for any individual aliquot. However, for samples with growth curves that deviate significantly from the gSGC, $D_{\mathrm{e}}$ values estimated from the latter may not be accurate.

\section{Discussion}

Equation 3 shows that the sensitivity-corrected regenerative dose OSL signals $\left(L_{\mathrm{x}} / T_{\mathrm{x}}\right)$ measured in the SAR procedure are dependent on two factors: the $k$ and $D_{0}$ values. The former is determined by sensitivity changes occurring between the natural or regenerative dose step and the measurement of the test dose signal in the same SAR cycle. The existence and extent of such sensitivity changes are expected to be sample-specific and contingent on the particular measurement conditions, for the reasons given below. 
In the SAR procedure, several laboratory treatments are administered to an aliquot between

340 the measurements of $L_{\mathrm{x}}$ and $T_{\mathrm{x}}$, including optical stimulation, irradiation and preheating. These 341 experimental conditions may influence the $k$ value and, hence, the shape of the DRC. For example, 342 OSL stimulation may de-sensitise the sample due to the recombination of luminescence centres with electrons excited from the OSL traps, reducing the number of hole centres subsequently available for radiative recombination (e.g., Bailey et al., 1997; Wintle and Murray, 1997; Bailey, 2001). In addition, irradiation may change the relative concentrations of luminescence centres and 'killer' (non-radiative) centres, causing dose quenching of sensitivity (Zimmerman, 1971). Furthermore, preheating may play an important role in changing the sensitivity of quartz OSL (Roberts et al., 1994; Stokes, 1994; Murray and Wintle, 1999b; Wintle and Murray, 1999). The $k$ value may, thus, be influenced by the experimental treatments applied ahead of the measurement of $T_{\mathrm{x}}$.

A further potential complication is that even if identical SAR procedures and measurement conditions are applied systematically to different samples, they may respond differently in terms of changes in sensitivity $(k)$. Such differences are to be expected, because not all grains on an aliquot will share the same irradiation, bleaching or thermal histories, and each of these may affect the luminescence properties (and, hence, the $k$ value). Fortunately, as demonstrated in principle by eqn. 6 and in practice by the data in Fig. 2 and 3, between-aliquot variations in $k$ can be reduced substantially by applying a normalisation using one of the regenerative dose signals. Re-normalisation cannot eliminate the uncertainty associated with any dose dependency in $\underline{k}$, but the latter is thought to have no influence on $D_{\mathrm{e}}$ estimation (Murray and Wintle, 2000; Wintle and Murray, 2006).

In addition to reducing the extent of variation in the DRCs for individual aliquots of the same sample, we have demonstrated that re-normalisation can also reduce the variation in DRCs between samples (Fig. 5 and 6). This allows the direct comparison of DRCs for different samples, even though they were measured in different laboratories using a range of experimental conditions (Table 1). The re-normalised DRCs of these samples have similar shapes up to a dose of $\sim 250 \mathrm{~Gy}$, beyond which the 
effects of saturation become more important, resulting in divergence of the re-normalised DRCs for one of the samples (MST-19). It has been demonstrated previously that the characteristic saturation dose $\left(D_{0}\right)$ of quartz OSL is strongly influenced by thermal treatment (Chen et al., 2001), and its value may be reduced significantly by heating to a high temperature (Lai et al., 2008; Gong et al., 2014). But the behaviour of the quartz OSL signal in the high-dose range remains poorly understood, including whether the linear component is a laboratory artefact or a meaningful physical property (e.g., Lowick and Preusser, 2011; Timar-Gabor et al., 2012). Based on these considerations, we do not recommend using the SGC method to estimate $D_{\mathrm{e}}$ values greater than $\sim 250 \mathrm{~Gy}$.

The establishment of a gSGC may greatly benefit OSL dating of quartz, in view of its compensating effect for inter-aliquot and inter-sample differences in $k$ and $D_{0}$ values, and will be especially useful for studies that require a large number of independent, single-aliquot estimates of $D_{\mathrm{e}}$. Because the re-normalisation method underpinning the gSGC is less dependent on the laboratory conditions used for measuring the OSL signal (Fig. 4) and reduces inter-aliquot variations to a much greater extent than the SGC method proposed by Roberts and Duller (2004), it should yield more precise and accurate estimates of $D_{\mathrm{e}}$. This is true for the samples examined here, as demonstrated in Fig. 8a: this shows the same data as displayed in Fig. 7a, but with SAR $D_{\mathrm{e}}$ values plotted against with the corresponding SGC $D_{\mathrm{e}}$ estimates (obtained by projecting the $L_{\mathrm{n}} / T_{\mathrm{n}}$ signal of each aliquot on to the respective sample-average $\left.L_{\mathrm{x}} / T_{\mathrm{x}} \mathrm{DRC}\right)$. The corresponding $D_{\mathrm{e}}$ ratios are presented in Fig. 8b,c. These plots reveal that, unlike the gSGC data in Fig. 7, large deviations can occur from a $D_{\mathrm{e}}$ ratio of unity, even for aliquots of the same sample using the sample-average $L_{\mathrm{x}} / T_{\mathrm{x}}$ DRC. These results are much poorer than those reported in previous studies (e.g., Roberts and Duller, 2004; Lai et al., 2007), which we attribute to the less homogeneous inter-aliquot behaviour of the samples investigated here.

By reducing inter-aliquot and inter-sample differences in DRC shape using the renormalisation procedure, it is feasible to tentatively construct a globally applicable SGC (Fig. 6). 
required to estimate $D_{\mathrm{e}}$ values using the gSGC is significantly less than that needed to make full SAR analyses. When making these measurements, we recommend that a regenerative dose close to the natural dose is chosen, to reduce the extent of between-aliquot variation in the re-normalised results 392 (Fig. 3).

Furthermore, following the original suggestion by Roberts and Duller (2004) that a limited number of aliquots could be analysed using a full SAR procedure to confirm whether application of a SGC is appropriate, we recommend that the complete SAR procedure should be applied to a few aliquots (4-6, say) from each sample or site, and the resultant DRCs compared against the gSGC to verify its suitability to estimate $D_{\mathrm{e}}$ values for the remaining aliquots. If a sample yields a renormalised DRC that deviates significantly from the gSGC described here - for example, the finegrain fraction of sample MST-19 (Fig. 6c) - then it may be necessary to estimate the $D_{\mathrm{e}}$ values for the remaining aliquots from measurements of $L_{\mathrm{n}}, T_{\mathrm{n}}, L_{\mathrm{r} 1}$ and $T_{\mathrm{r} 1}$ and the re-normalised DRC specific to that sample, using eqn. 10.

By examining some aliquots using the full SAR procedure - including routine tests for IR depletion of the OSL signal, recycling ratio and recuperation - each sample can be checked for its luminescence behaviour and SAR performance. Satisfactory outcomes of these tests can be used as acceptance criteria to then apply the gSGC method to the remaining aliquots with confidence. Incorporating such tests directly in the gSGC procedure would substantially increase the measurement time and, thus, diminish one of the chief benefits of the gSGC approach.

The OSL signals of the samples investigated in this study are dominated by the fast component (see Fig. 1 and the references in Table 1), so we expect the gSGC established here to be applicable only to other such samples. The DRC shapes of other components of quartz OSL may be significantly different; for example, the slow components may saturate at much higher doses

412 (Singarayer et al., 2000; Singarayer and Bailey, 2003). The ultrafast and medium components of the 413 OSL signal may also exhibit some undesirable properties, such as thermal instability, and these can 
414 also adversely influence the accuracy of $D_{\text {e }}$ estimates (e.g., Li and Li, 2006; Jain et al., 2008). As a

415 result, the existence of a common DRC among different samples does not necessarily imply that

416 reliable age estimates will be obtained. Hence, dose recovery tests (Roberts et al., 1999) and age

417 checks against independently dated samples need to be performed to demonstrate that a series of

418 known doses can be accurately determined from the re-normalised DRC.

Finally, the aliquots measured in this study each consisted of a few hundred to a few thousand quartz grains, depending on the grain size used. Between-grain differences in luminescence behaviour, such as large variations in DRC shape and $D_{0}$ values (e.g., Roberts et al., 1999; Jacobs et al., 2003, 2013), will be homogenised in multi-grain aliquots. While this offers benefits in terms of enabling a gSGC to be constructed for single aliquots, the use of multi-grain aliquots sacrifices the advantages of single-grain dating (e.g., Jacobs and Roberts, 2007; Duller, 2008). Future research could usefully examine whether the re-normalisation and gSGC procedures can be extended to individual grains of quartz from the same and different samples. The application of these procedures to single-grain OSL dating would maximise the benefits of gSGC construction, greatly reducing the amount of instrument time needed to measure each sample and, thereby, making it practicable to determine $D_{\mathrm{e}}$ values for a much larger number of individual grains. If it is found, however, that single grains are too variable in their OSL behaviours to follow a gSGC, then it would be instructive to determine the smallest aliquot size that can satisfactorily homogenise these grain-to-grain differences.

\section{Conclusions}

Single aliquots of sedimentary quartz commonly exhibit large variations in the shape of the DRCs constructed from the sensitivity-corrected regenerative dose signals $\left(L_{\mathrm{x}} / T_{\mathrm{x}}\right)$. This variability can arise from inter-aliquot variation in the extent of sensitivity change between the natural or regenerative dose step and the subsequent test dose measurement in the same SAR cycle. We have shown in this paper that such variation can be reduced greatly by applying a normalisation procedure using one of the regenerative dose OSL signals ('re-normalisation'). For a range of quartz samples 
439 from different regions of Asia, Africa, Europe and North America, we construct a common re-

440 normalised DRC up to a dose of $\sim 250 \mathrm{~Gy}$, which we tentatively propose as a 'global standardised

441 growth curve' (gSGC) for single aliquots of quartz. Equivalent doses can be estimated for other

442 samples using the fitting parameters for the gSGC developed here, together with measurements of the

443 natural signal $\left(L_{\mathrm{n}}\right)$, one regenerative dose signal $\left(L_{\mathrm{x} 1}\right)$ and the corresponding test dose signals $\left(T_{\mathrm{n}}, T_{\mathrm{x} 1}\right)$

444 for each aliquot. When compared to the construction of a full DRC for each aliquot using

445 conventional SAR procedures, the re-normalisation and gSGC procedures described here require

446 much less instrument time, thereby enabling the measurement of $D_{\mathrm{e}}$ values for many more aliquots of

447 each sample.

\section{Acknowledgements}

This study was supported by a University of Wollongong Vice-Chancellor's Postdoctoral Research Fellowship to B.L., an Australian Research Council Australian Laureate Fellowship to R.G.R. (FL130100116), an Australian Research Council Queen Elizabeth II Fellowship to Z.J. (DP1092843), and a grant to S.H.L. from the Research Grants Council of the Hong Kong Special Administrative Region, China (7028/08P). We also thank Yasaman Jafari for assistance with sample preparation and both anonymous reviewers for their constructive comments. 
460

Aitken, M.J., 1998. An Introduction to Optical Dating. Oxford University Press, Oxford.

Bailey, R.M., 2001. Towards a general kinetic model for optically and thermally stimulated luminescence of quartz. Radiation Measurements 33, 17-45.

Bailey, R.M., Smith, B.W., Rhodes, E.J., 1997. Partial bleaching and the decay form characteristics of quartz OSL. Radiation Measurements 27, 123-136.

Bøtter-Jensen, L., Bulur, E., Duller, G.A.T., Murray, A.S., 2000. Advances in luminescence instrument systems. Radiation Measurements 32, 523-528.

Burbidge, C.I., Duller, G.A.T., Roberts, H.M., 2006. $D_{\mathrm{e}}$ determination for young samples using the standardised OSL response of coarse-grain quartz. Radiation Measurements 41, 278-288.

Chen, G., Murray, A.S., Li, S.H., 2001. Effect of heating on the quartz dose-response curve. Radiation Measurements 33, 59-63.

Duller, G.A.T., 2003. Distinguishing quartz and feldspar in single grain luminescence measurements. Radiation Measurements 37, 161-165.

Duller, G.A.T., 2008. Single-grain optical dating of Quaternary sediments: why aliquot size matters in luminescence dating. Boreas 37, 589-612.

Galbraith, R.F., Roberts, R.G., Laslett, G.M., Yoshida, H., Olley, J.M., 1999. Optical dating of single and multiple grains of quartz from Jinmium rock shelter, northern Australia: Part I, experimental design and statistical models. Archaeometry 41, 339-364.

Gong, Z.J., Sun, J.M., Lü, T.Y., Tian, Z.H., 2014. Investigating the optically stimulated luminescence dose saturation behavior for quartz grains from dune sands in China. Quaternary Geochronology 22, 137-143.

Jacobs, Z., Duller, G.A.T., Wintle, A.G., 2003. Optical dating of dune sand from Blombos Cave: IIsingle grain data. Journal of Human Evolution 44, 613-625.

Jacobs, Z., Hayes, E.H., Roberts, R.G., Galbraith, R.F., Henshilwood, C.S., 2013. An improved OSL chronology for the Still Bay layers at Blombos Cave, South Africa: further tests of single-grain dating procedures and a re-evaluation of the timing of the Still Bay industry across southern Africa. Journal of Archaeological Science 40, 579-594.

Jacobs, Z., Roberts, R.G., 2007. Advances in optically stimulated luminescence dating of individual grains of quartz from archeological deposits. Evolutionary Anthropology 16, 210-223.

Jain, M., Choi, J.H., Thomas, P.J., 2008. The ultrafast OSL component in quartz: Origins and implications. Radiation Measurements 43, 709-714.

Lai, Z.P., 2006. Testing the use of an OSL standardised growth curve (SGC) for $D_{\mathrm{e}}$ determination on quartz from the Chinese Loess Plateau. Radiation Measurements 41, 9-16.

Lai, Z.P., 2010. Chronology and the upper dating limit for loess samples from Luochuan section in the Chinese Loess Plateau using quartz OSL SAR protocol. Journal of Asian Earth Sciences 37, 176-185.

Lai, Z.P., Bruckner, H., Fulling, A., Zoller, L., 2008. Effects of thermal treatment on the growth curve shape for OSL of quartz extracted from Chinese loess. Radiation Measurements 43, 763-766.

Lai, Z.P., Bruckner, H., Zoller, L., Fulling, A., 2007. Existence of a common growth curve for siltsized quartz OSL of loess from different continents. Radiation Measurements 42, 1432-1440.

$\mathrm{Li}, \mathrm{B} ., \mathrm{Li}, \mathrm{S} . \mathrm{H} ., 2$ 2006. Comparison of $D_{\mathrm{e}}$ estimates using the fast component and the medium component of quartz OSL. Radiation Measurements 41, 125-136.

Li, B., Li, S.H.,Sun, J.M., 2011. Isochron dating of sand-loess-soil deposits from the Mu Us Desert margin, central China. Quaternary Geochronology 6, 556-563.

Li, S.H., Sun, J.M., Zhao, H., 2002. Optical dating of dune sands in the northeastern deserts of China. Palaeogeography Palaeoclimatology Palaeoecology 181, 419-429.

Long, H., Lai, Z.P., Fan, Q.S., Sun, Y.J., Liu, X.J., 2010. Applicability of a quartz OSL standardised growth curve for $D_{\mathrm{e}}$ determination up to $400 \mathrm{~Gy}$ for lacustrine sediments from the Qaidam Basin of the Qinghai-Tibetan Plateau. Quaternary Geochronology 5, 212-217. 
Lowick, S.E., Preusser, F., 2011. Investigating age underestimation in the high dose region of optically stimulated luminescence using fine grain quartz. Quaternary Geochronology 6, 33-41.

Murray, A.S., Roberts, R.G., 1998. Measurement of the equivalent dose in quartz using a regenerative-dose single-aliquot protocol. Radiation Measurements 29, 503-515.

Murray, A.S., Wintle, A.G., 1999a. Isothermal decay of optically stimulated luminescence in quartz. Radiation Measurements 30, 119-125.

Murray, A.S., Wintle, A.G., 1999b. Sensitisation and stability of quartz OSL: Implications for interpretation of dose-response curves. Radiation Protection Dosimetry 84, 427-432.

Murray, A.S., Wintle, A.G., 2000. Luminescence dating of quartz using an improved single-aliquot regenerative-dose protocol. Radiation Measurements 32, 57-73.

Roberts, H.M., Duller, G.A.T., 2004. Standardised growth curves for optical dating of sediment using multiple-grain aliquots. Radiation Measurements 38, 241-252.

Roberts, R.G., Galbraith, R.F., Olley, J.M., Yoshida, H., Laslett, G.M., 1999. Optical dating of single and multiple grains of quartz from Jinmium rock shelter, northern Australia: Part II, results and implications. Archaeometry 41, 365-395.

Roberts, R.G., Spooner, N.A., Questiaux, D.G., 1994. Palaeodose underestimates caused by extendedruation preheats in the optical dating of quartz. Radiation Measurements 23, 647-653.

Shen, Z.X., Mauz, B., 2011. Estimating the equivalent dose of late Pleistocene fine silt quartz from the Lower Mississippi Valley using a standardized OSL growth curve. Radiation Measurements 46, 649-654.

Singarayer, J.S., Bailey, R.M., 2003. Further investigations of the quartz optically stimulated luminescence components using linear modulation. Radiation Measurements 37, 451-458.

Singarayer, J.S., Bailey, R.M., Rhodes, E.J., 2000. Potential of the slow component of quartz OSL for age determination of sedimentary samples. Radiation Measurements 32, 873-880.

Stokes, S., 1994. The timing of OSL sensitivity changes in a natural quartz. Radiation Measurements 23, 601-605.

Sun, J.M., Ding, Z.L., Liu, T.S., Rokosh, D., Rutter, N., 1999. 580,000-year environmental reconstruction from aeolian deposits at the Mu Us Desert margin, China. Quaternary Science Reviews 18, 1351-1364.

Sun, J.M., Li, S.H., Muhs, D.R., Li, B., 2007. Loess sedimentation in Tibet: provenance, processes, and link with Quaternary glaciations. Quaternary Science Reviews 26, 2265-2280.

Telfer, M.W., Bateman, M.D., Carr, A.S., Chase, B.M., 2008. Testing the applicability of a standardized growth curve (SGC) for quartz OSL dating: Kalahari dunes, South African coastal dunes and Florida dune cordons. Quaternary Geochronology 3, 137-142.

Timar-Gabor, A., Vasiliniuc, S., Vandenberghe, D.A.G., Cosma, C., Wintle, A.G., 2012. Investigations into the reliability of SAR-OSL equivalent doses obtained for quartz samples displaying dose response curves with more than one component. Radiation Measurements 47, 740-745.

Wintle, A.G., Murray, A.S., 1997. The relationship between quartz thermoluminescence, phototransferred thermoluminescence, and optically stimulated luminescence. Radiation Measurements 27, 611-624.

Wintle, A.G., Murray, A.S., 1999. Luminescence sensitivity changes in quartz. Radiation Measurements 30, 107-118.

Wintle, A.G., Murray, A.S., 2006. A review of quartz optically stimulated luminescence characteristics and their relevance in single-aliquot regeneration dating protocols. Radiation Measurements 41, 369-391.

Zimmerman, J., 1971. The radiation-induced increase of the $100^{\circ} \mathrm{C}$ thermoluminescence sensitivity of fired quartz. Journal of Physics C: Solid State Physics 4, 3265-3276. 


\section{Figure captions}

Figure 1: Natural OSL decay curves for single aliquots of quartz from six Chinese samples. All curves are normalised to unity at $\mathrm{t}=0$ for comparison. The quartz grains were preheated at $260^{\circ} \mathrm{C}$ for $10 \mathrm{~s}$ and then stimulated at $125^{\circ} \mathrm{C}$ using blue LEDs. The inset plot shows that the natural signal of DGF-1 is dominated by the fast component of quartz OSL. Three exponential decay functions were fitted to the decay curve to determine the relative contributions of the fast, medium and slow (plus background, BG) components. The other samples are similarly dominated by the fast component.

Figure 2: The sensitivity-corrected natural $\left(L_{\mathrm{n}} / T_{\mathrm{n}}\right.$, marked as $\left.\mathrm{N}\right)$ and regenerative dose $\left(L_{\mathrm{x}} / T_{\mathrm{x}}\right)$ signals (both plotted on the left-hand axis) and their re-normalised counterparts (right-hand axis). The latter were calculated using the re-normalisation procedure described in the text, in which one of the $L_{\mathrm{x}} / T_{\mathrm{x}}$ signals (indicated by the arrow) is chosen for each of the samples. Note that the re-normalised data (circles) are offset by a few Gy to the right on the $x$-axis for clarity.

Figure 3: The relative standard deviation (RSD, the standard deviation divided by the mean) for the sensitivity-corrected (no normalisation) and re-normalised $L_{\mathrm{x}} / T_{\mathrm{x}}$ signals of sample $\mathrm{Sm} 5$, plotted against the corresponding regenerative doses. The regenerative dose used for normalisation of each data set is shown in the legend. The RSD for the sensitivity-corrected natural $\left(L_{\mathrm{n}} / T_{\mathrm{n}}\right)$ signal is shown on the $y$-axis. The RSD values at zero regenerative dose are not shown; they are high $(\sim 50 \%)$ due to the low absolute ratios of $L_{\mathrm{x}} / T_{\mathrm{x}}$ at $0 \mathrm{~Gy}$, but the absolute standard deviations are negligible compared to those at higher regenerative doses.

Figure 4: (a) The test dose-corrected signals $\left[\left(L_{\mathrm{x}} / T_{\mathrm{x}}\right)^{*} D_{\mathrm{t}}\right]$ for sample DGF-1 measured under various experimental conditions, plotted against the corresponding regenerative doses; the test dose-corrected natural signals $\left(\left[\left(L_{\mathrm{n}} / T_{\mathrm{n}}\right) * D_{\mathrm{t}}\right]\right)$ are shown on the $y$-axis and marked as $\mathrm{N}$. The legend indicates the preheat/cut-heat temperatures (in ${ }^{\circ} \mathrm{C}$ ) applied to the regenerative and test doses, respectively, followed by the size of the test dose. (b) The same data as in (a) after re-normalisation.

Figure 5: (a) The test dose-corrected signals for various samples from China (6 aliquots of each), plotted against the corresponding regenerative doses. (b) The re-normalised $L_{\mathrm{x}} / T_{\mathrm{x}}$ signals obtained by multiplying 
each of the data sets in (a) so that they pass through a value of unity at $172 \mathrm{~Gy}$. This is equivalent to renormalising each data set using the regenerative dose signal at $172 \mathrm{~Gy}$. The dashed line shows the best-fit curve using a saturating exponential function plus a linear component.

Figure 6: (a) The test dose-corrected signals for various samples from different regions of the world (Table 1; the average and standard deviation of 6 aliquots is shown for each sample), plotted against the corresponding regenerative doses. (b) The re-normalised $L_{\mathrm{x}} / T_{\mathrm{x}}$ signals obtained by multiplying each of the data sets in (a) so that they pass through a value of unity at $172 \mathrm{~Gy}$. The dotted and dashed lines are the best-fit curves to the data of MST-19 (FG) and MST-19 (CG) (Timar-Gabor et al., 2012) and 'synthetic' sample TNE (Roberts and Duller, 2004), as provided in the original papers. (c) The same data sets as shown in (b), but restricted to the 0-250 Gy dose range. The solid black lines in (b) and (c) are the best-fit curves determined using a saturating exponential function plus a linear component (Table 2 lists the corresponding fitting parameters).

Figure 7: (a) $D_{\mathrm{e}}$ estimates for 56 single aliquots of the 7 Chinese samples measured in this study (Table 1). $D_{\mathrm{e}}$ values were estimated in two ways: from the gSGC in Fig. $6 \mathrm{~b}\left(\mathrm{gSGC} D_{\mathrm{e}}\right)$ and from construction of full SAR growth curve for each aliquot (SAR $D_{\mathrm{e}}$ ). (b) The ratios of the gSGC and SAR $D_{\mathrm{e}}$ values plotted against the latter. (c) A radial plot of the same data as shown in (b). The data up to 250 Gy are shown as filled symbols, and those $>250$ Gy as open symbols, in each plot.

Figure 8: (a) The same data as shown in Fig. 7a, but with the $D_{\mathrm{e}}$ values estimated from the individual SGC curve specific to each sample (i.e., the average $L_{\mathrm{x}} / T_{\mathrm{x}} \mathrm{DRC}$ for a particular sample), plotted against the SAR $D_{\mathrm{e}}$ for each aliquot. (b) The ratios of the individual $L_{\mathrm{x}} / T_{\mathrm{x}}$ SGC and SAR $D_{\mathrm{e}}$ values plotted against the latter. (c) A radial plot of the same data as shown in (b). The data up to 250 Gy are shown as filled symbols, and those $>250 \mathrm{~Gy}$ as open symbols, in each plot. 


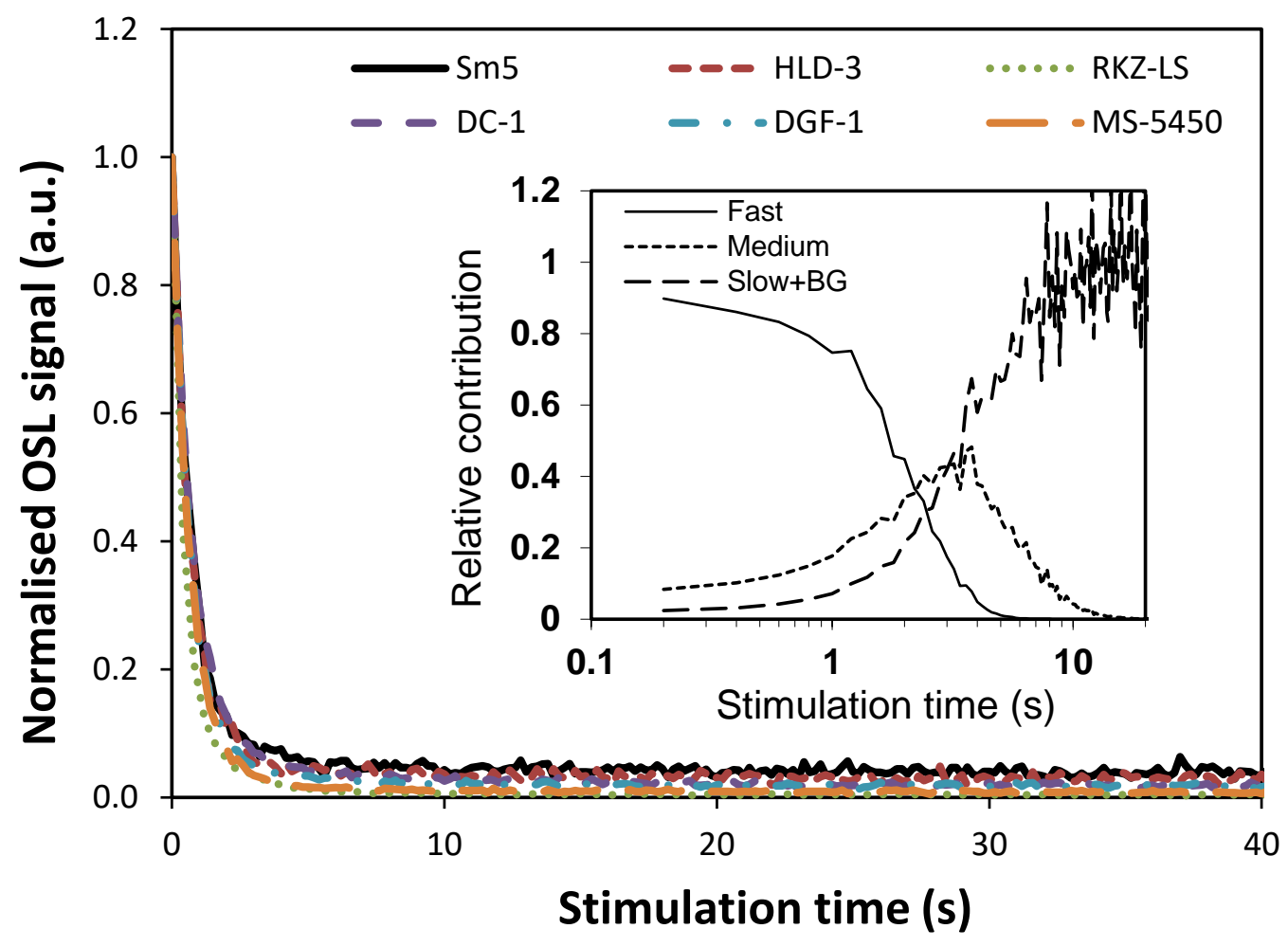

Figure 1 

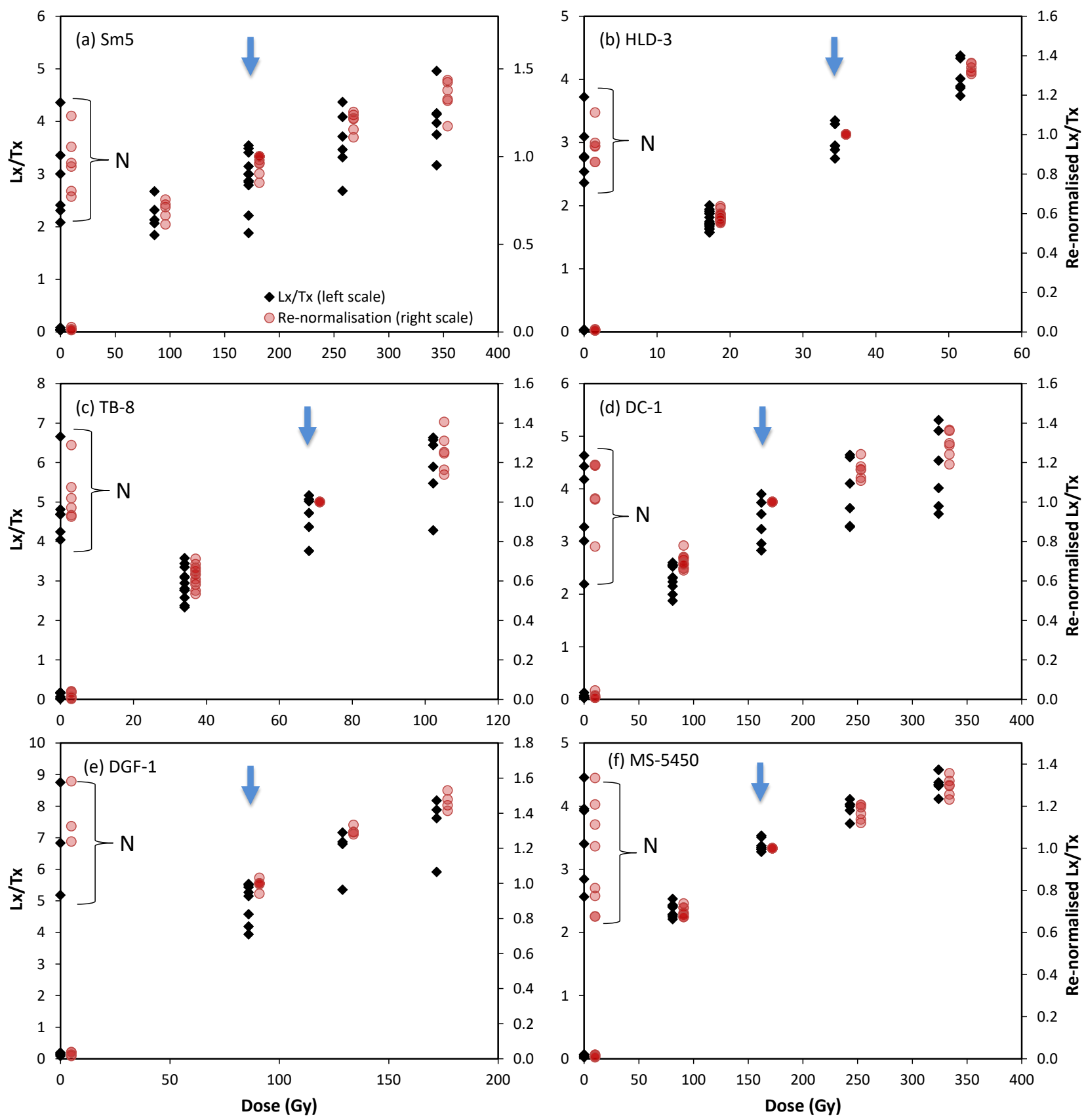

Figure 2 


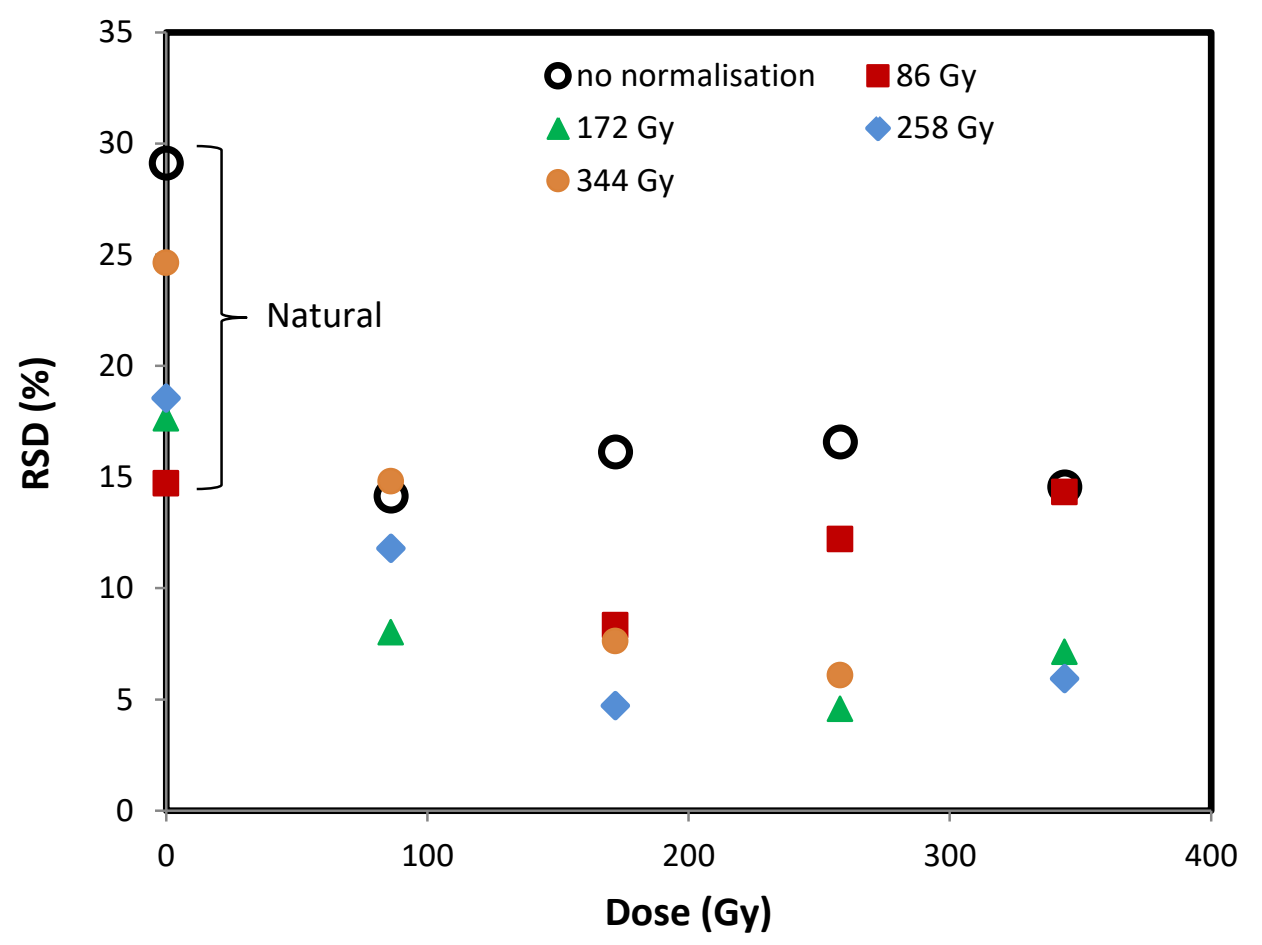

Figure 3 

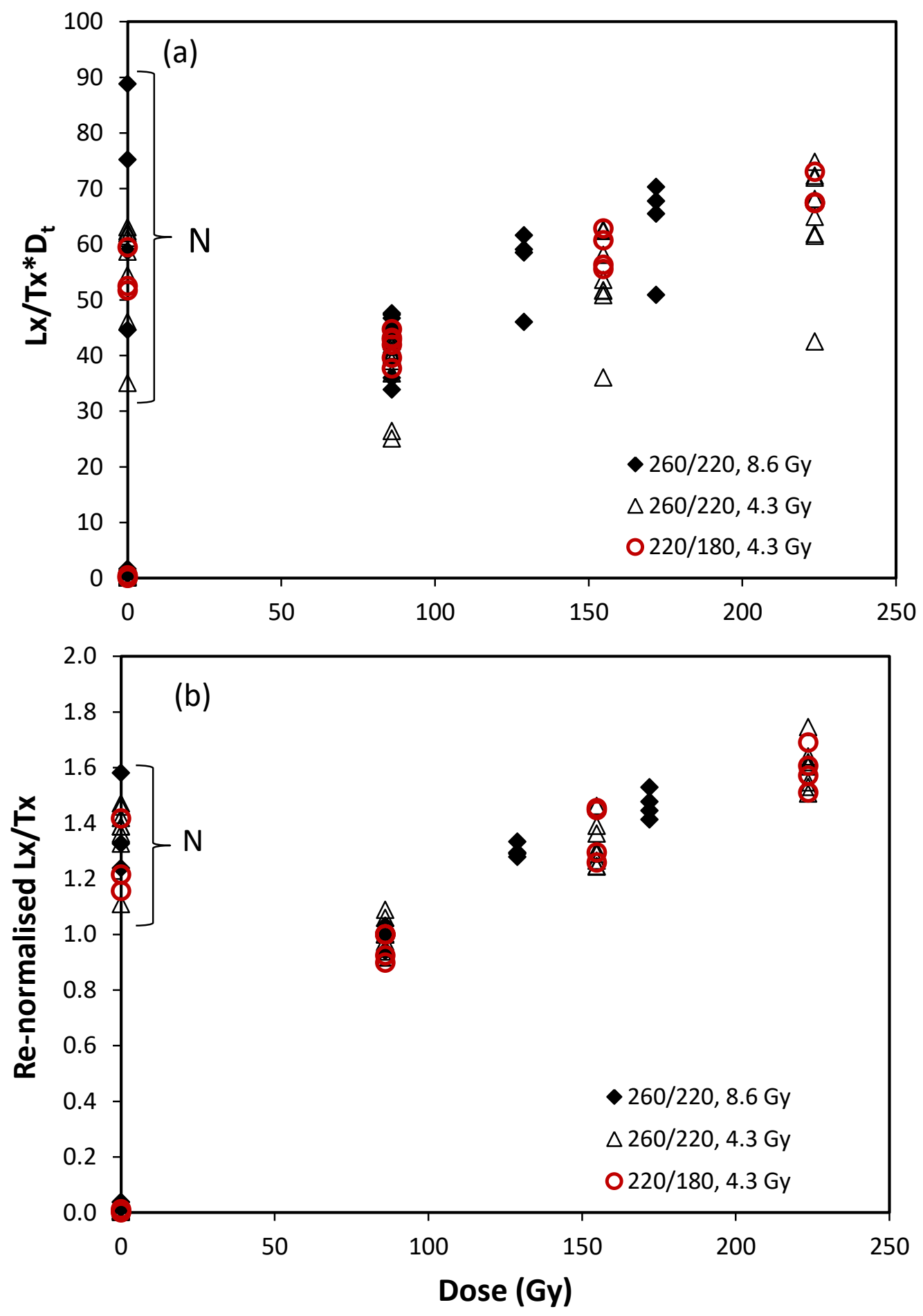

Figure 4 

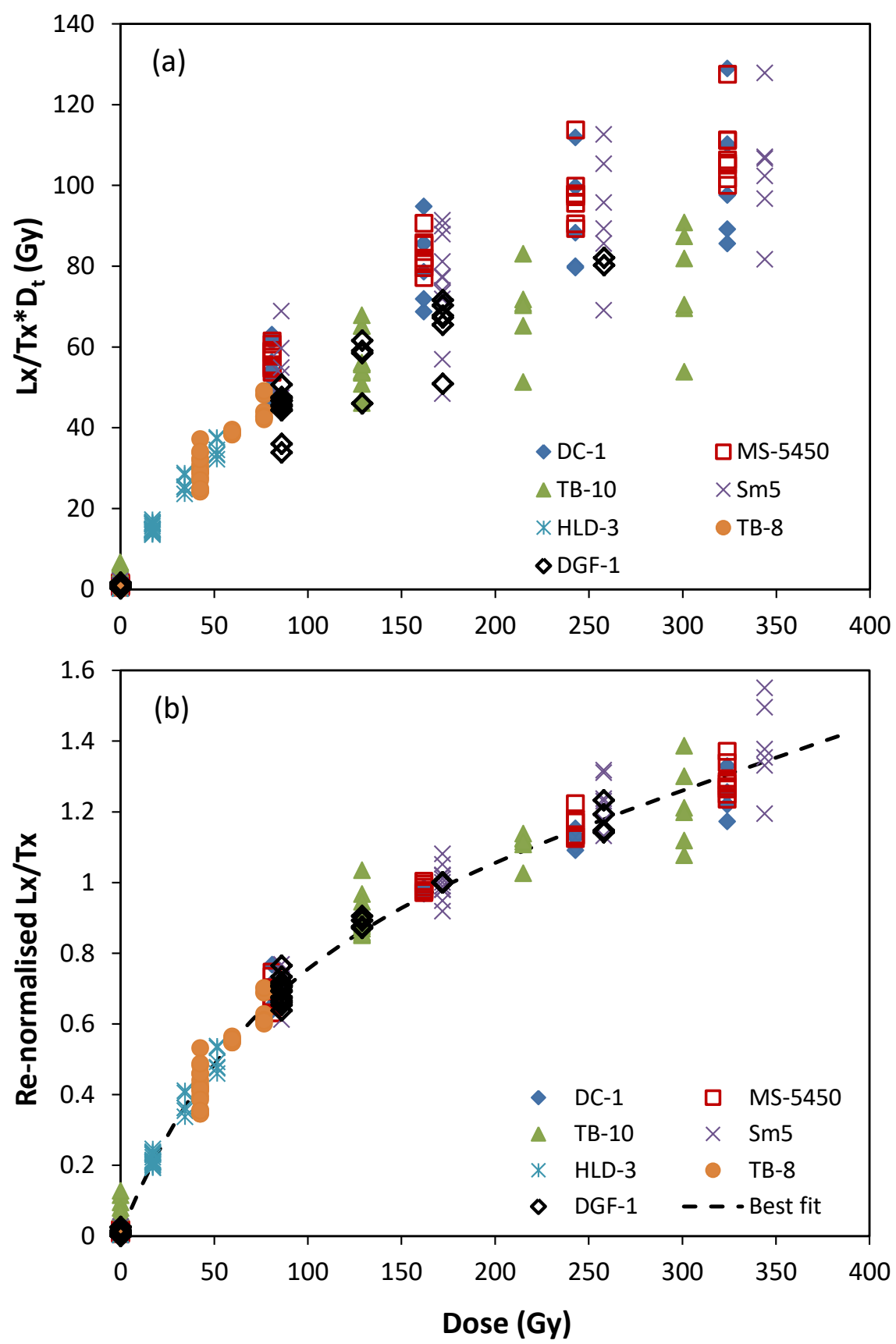

Figure 5 

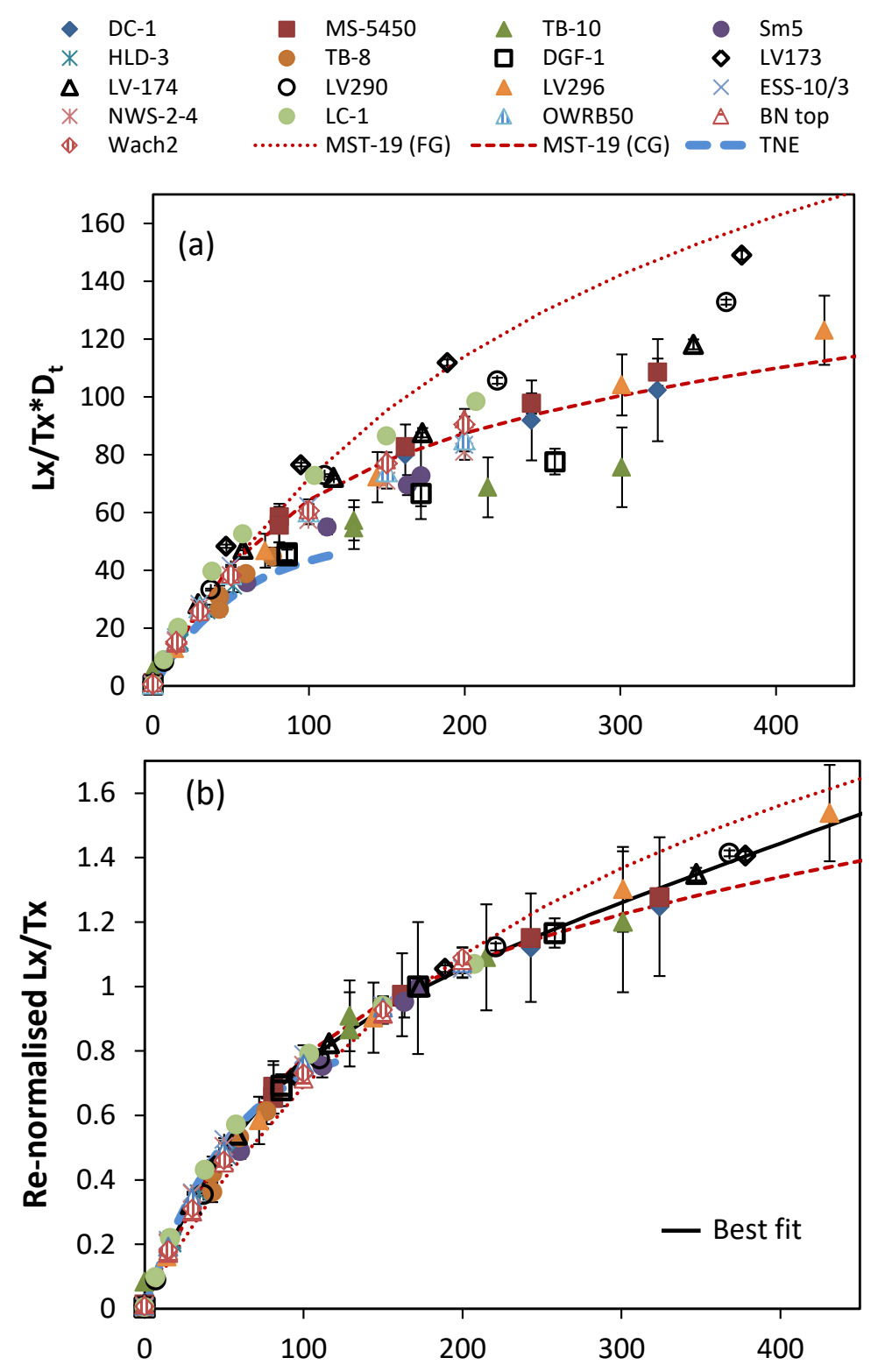

Figure 6

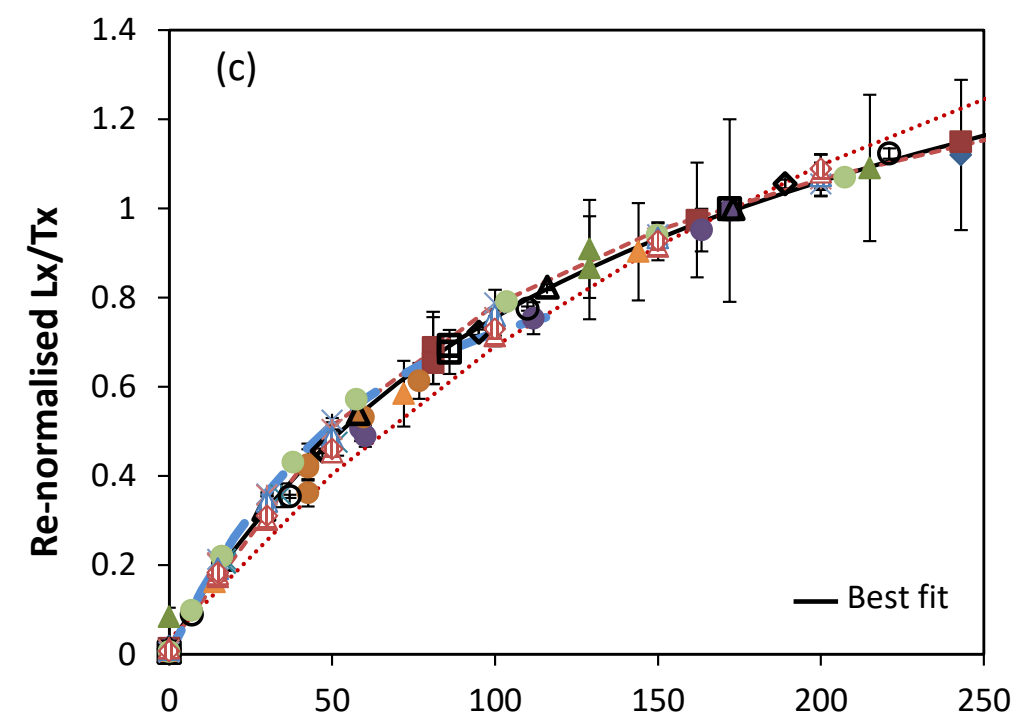



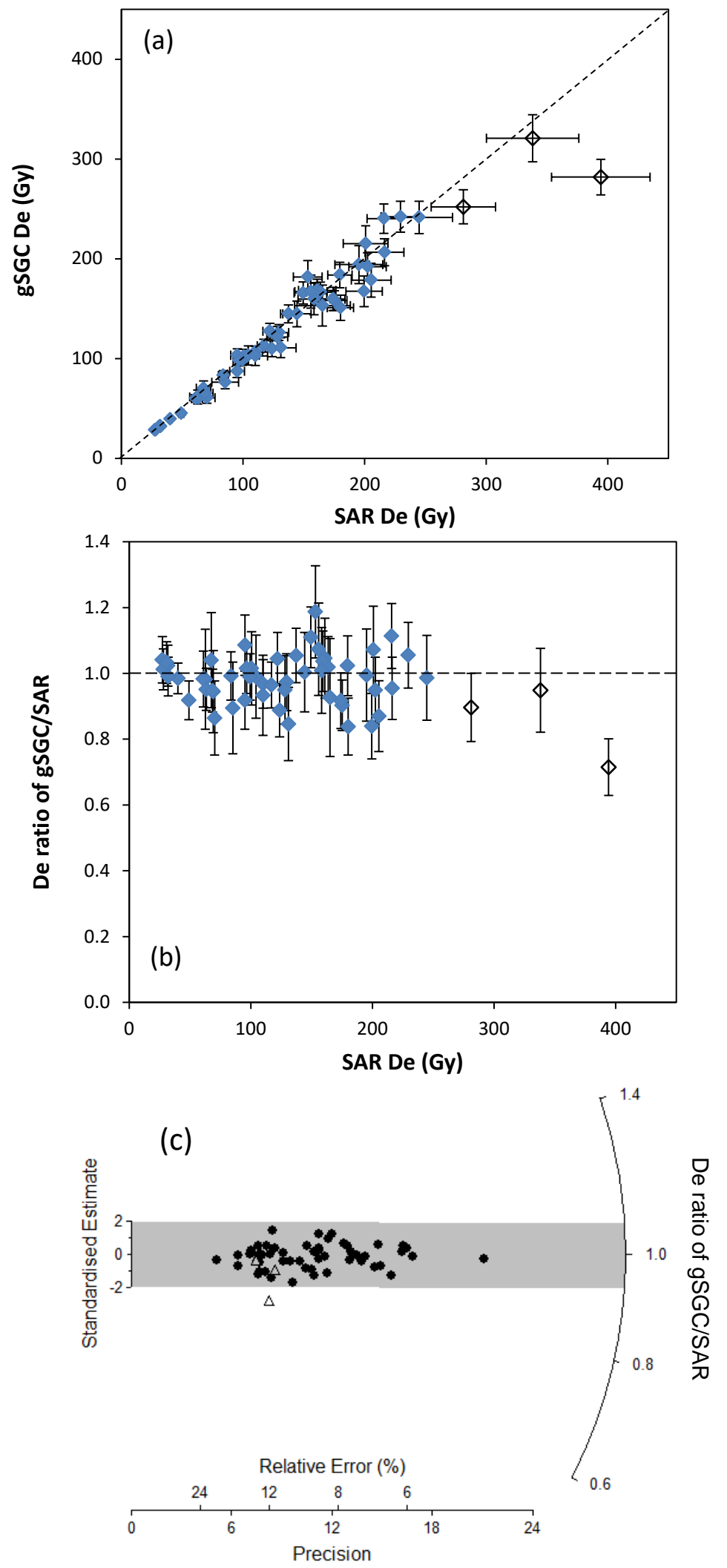

Figure 7 

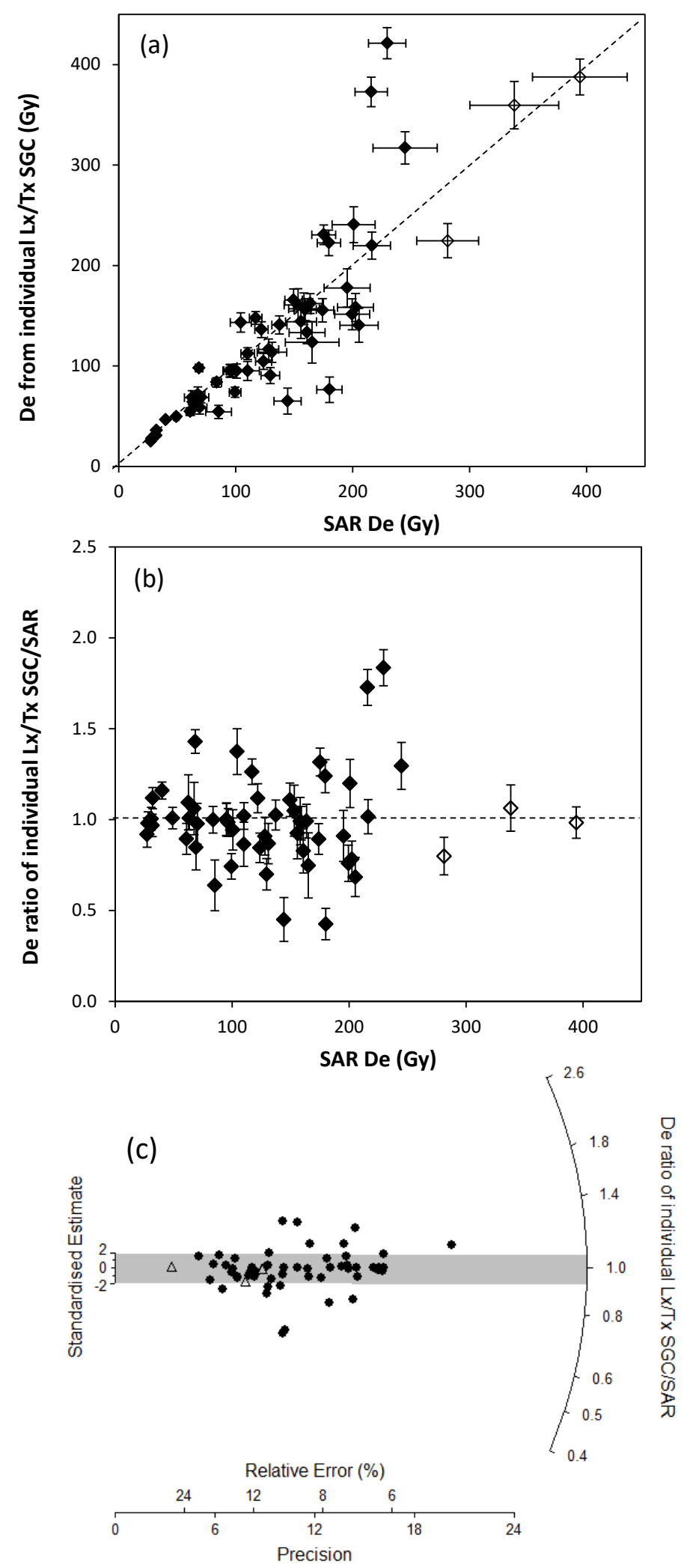

Figure 8 
Table 1: Summary of study samples, including their geographic locations, depositional environments, and the grain size and measurement conditions used to determine the equivalent dose $\left(D_{\mathrm{e}}\right)$ values. The ranges of $D_{\mathrm{e}}$ values estimated using individual SAR DRCs are listed for the 7 Chinese samples measured in this study, and the approximate $D_{\mathrm{e}}$ values (if reported by the original authors) are listed for the other samples. Shen and Mauz (2011) did not provide $D_{\mathrm{e}}$ values for their samples, so approximate $D_{\mathrm{e}}$ values have been estimated from the sensitivity-corrected natural $\left(L_{\mathrm{n}} / T_{\mathrm{n}}\right)$ and regenerative dose $\left(L_{\mathrm{x}} / T_{\mathrm{x}}\right)$ ratios provided by the authors. Data on OSL sensitivity to a test dose (in counts per Gy) are provided only for the samples measured in this study and were obtained from 6 aliquots of each sample.

\begin{tabular}{|c|c|c|c|c|c|c|c|c|c|}
\hline Sample & Location & $\begin{array}{l}\text { Sediment } \\
\text { type }\end{array}$ & $\begin{array}{l}\text { Grain size } \\
\quad(\mu \mathrm{m})\end{array}$ & $\begin{array}{c}\text { Preheat/ } \\
\text { cut-heat } \\
\left({ }^{\circ} \mathrm{C}\right)\end{array}$ & $\begin{array}{l}\text { Test dose } \\
\quad(\mathbf{G y})\end{array}$ & $\begin{array}{l}\text { Test dose } \\
\text { sensitivity } \\
\text { (cts/Gy) }\end{array}$ & $D_{\mathrm{e}}(\mathbf{G y})$ & $D_{0}(\mathbf{G y})^{a}$ & Data source \\
\hline DC-1 & Shanxi, China & Fluvial & $150-212$ & $260 / 220$ & 24.3 & $1563-3079$ & $100-250$ & $114 \pm 8$ & This work \\
\hline DGF-1 & Mu Us Desert, China & Lake & $90-150$ & $260 / 220$ & 8.6 & $87-200$ & $130-180$ & $116 \pm 18$ & This work \\
\hline HLD-3 & Hulun Buir Desert, China & Dune & $90-150$ & $260 / 220$ & 8.6 & $251-1439$ & $27-40$ & $-{ }^{a}$ & This work \\
\hline MS-5450 & Henan, China & Loess & $90-150$ & $260 / 220$ & 24.3 & $64-270$ & $96-340$ & $124 \pm 9$ & This work \\
\hline Sm5 & Mu Us Desert, China & Dune & $90-150$ & $260 / 220$ & 25.8 & $121-205$ & $100-394$ & $138 \pm 15$ & This work \\
\hline TB-8 & Tibet, China & Loess & $90-150$ & $260 / 220$ & 8.5 & $175-260$ & $62-104$ & $-{ }^{a}$ & This work \\
\hline TB-10 & Tibet, China & Loess & $90-150$ & $260 / 220$ & 17.2 & $31-100$ & $>300$ & $118 \pm 10$ & This work \\
\hline LV173 & Mississippi Valley, USA & Fluvial & $11-15$ & $220 / 180$ & 23.7 & - & $\sim 500$ & $174 \pm 18$ & Shen and Mauz, 2011 \\
\hline LV174 & Mississippi Valley, USA & Fluvial & $11-15$ & $220 / 180$ & 11.6 & - & $\sim 130$ & $141 \pm 16$ & Shen and Mauz, 2011 \\
\hline LV290 & Mississippi Valley, USA & Fluvial & $4-11$ & $220 / 180$ & 7.4 & - & $\sim 400$ & $168 \pm 16$ & Shen and Mauz, 2011 \\
\hline LV296 & Mississippi Valley, USA & Fluvial & $4-11$ & $220 / 180$ & 3.6 & - & $\sim 280$ & $189 \pm 21$ & Shen and Mauz, 2011 \\
\hline MST-19 (CG) & Romania & Loess & $63-90$ & $220 / 180$ & 17 & - & $288 \pm 57$ & $142 \pm 11$ & Timar-Gabor et al., 2012 \\
\hline MST-19 (FG) & Romania & Loess & $4-11$ & $220 / 180$ & 17 & - & $289 \pm 9$ & $250 \pm 8$ & Timar-Gabor et al., 2012 \\
\hline $\mathrm{LC}-1$ & Shanxi, China & Loess & $38-63$ & $260 / 220$ & 25.9 & - & $\sim 27$ & $88 \pm 5$ & Lai, 2006 \\
\hline NWS-2-4 & Germany & Loess & $38-63$ & $260 / 220$ & 11.3 & - & - & $98 \pm 9$ & Lai et al., 2007 \\
\hline OWRB50 & Wauneta, USA & Loess & $38-63$ & $260 / 220$ & 11.3 & - & - & $105 \pm 7$ & Lai et al., 2007 \\
\hline Wach2 & Wach, USA & Loess & $38-63$ & $260 / 220$ & 11.3 & - & - & $130 \pm 11$ & Lai et al., 2007 \\
\hline BN top & Bignell Hill, USA & Loess & $38-63$ & $260 / 220$ & 11.3 & - & - & $139 \pm 13$ & Lai et al., 2007 \\
\hline ESS-10/3 & Morocco & Fluvial & $38-63$ & $260 / 220$ & 11.3 & - & - & $85 \pm 5$ & Lai et al., 2007 \\
\hline $\mathrm{TNE}^{\mathrm{b}}$ & Tasmania, Australia & Dune & $180-212$ & $160 / 160$ & $0.7-4$ & - & - & $55 \pm 1$ & Roberts and Duller, 2004 \\
\hline
\end{tabular}

${ }^{a} D_{0}$ values were obtained by fitting the average dose response curves for each sample using a single saturating exponential function. The maximum regenerative doses given to samples HLD-3 and TB-8 were too small ( $<80 \mathrm{~Gy}$ ) to reliably estimate their $D_{0}$ values.

b TNE is a 'synthetic' sample based on 27 aliquots from 6 samples (Roberts and Duller, 2004). Data for the individual samples were not provided by the authors. 
Table 2: Summary of the best-fitting parameters for the data sets in Fig. $6 \mathrm{~b}(0-450$ Gy) and Fig. 6c (0-250 Gy), using a saturating exponential function plus a linear component $\left(Y=A\left[1-\exp \left(-X / D_{0}\right)\right]+c X+Y_{0}\right)$.

\begin{tabular}{|c|c|c|}
\hline Signal & Fitting data of 0-450 Gy & Fitting data of 0-250 Gy \\
\hline$A$ & $0.723 \pm 0.014$ & $0.787 \pm 0.051$ \\
\hline$D_{0}$ & $65.1 \pm 0.9$ & $73.9 \pm 2.2$ \\
\hline$c$ & $0.001784 \pm 0.000016$ & $0.001539 \pm 0.000068$ \\
\hline$Y_{0}$ & $0.009159 \pm 0.004795$ & $0.01791 \pm 0.00490$ \\
\hline
\end{tabular}

